\title{
Identification at the crime scene: The sooner, the better? The interpretation of rapid identification information by CSIs at the crime scene
}

Madeleine de Gruijter, Claire Nee \& Christianne J de Poot

\begin{abstract}
New technologies will allow Crime Scene Investigators (CSIs) in the near future to analyse traces at the crime scene and receive identification information while still conducting the investigation. These developments could have considerable effects on the way an investigation is conducted. CSIs may start reasoning based on possible database-matches which could influence scenario formation (i.e. the construction of narratives that explain the observed traces) during very early phases of the investigation. The goal of this study is to gain more insight into the influence of the rapid identification information on the reconstruction of the crime and the evaluation of traces by addressing two questions, namely 1 ) is scenario formation influenced from the moment that ID information is provided and 2) do database matches influence the evaluation of traces and the reconstruction of the crime. We asked 48 CSIs from England to investigate a potential murder crime scene on a computer. Our findings show that the interpretation of the crime scene by CSIs is affected by the moment identification information is provided. This information has a higher influence on scenario formation when provided after an initial scenario has been formed. Also, CSIs seem to attach great value to traces that produce matches with databases and hence yield a name of a known person. Similar traces that did not provide matches were considered less important. We question whether this kind of selective attention is desirable as it may cause ignorance of other relevant information at the crime scene.
\end{abstract}

Keywords:

Crime scene investigation

Rapid identification

Cognitive bias

Decision making

Scenario construction

Database-match 
Identification at the crime scene

\subsection{Introduction}

In the near future, Crime Scene Investigators (CSIs) will be able to select traces to analyse with rapid identification technologies and hence receive identification information about the sources of these traces while conducting the investigation at the crime scene [1,2]. Potentially, these developments may have large effects on the way an investigation is conducted. If traces can already be analysed during the crime scene investigation, reception of results may influence the decision-making resulting in the scenario formation (i.e. the construction of narratives that explain the observed traces at the crime scene) during the first phase of the investigation. Studies on police investigations show that detectives (who will be relying in part on evidence gathered by CSIs) create narrative events when they try to solve crimes [3,4]. Their expertise allows them to rapidly select relevant clues and form preliminary hypotheses $[5,6]$. An important consequence of this approach is that information that does not fit with a scenario chosen by the detective might be omitted from the account [3]. In general, people assign more weight to information acquired early on in the investigation than to information acquired later $[7,8]$. As a consequence, identification information provided early in the investigation may become dominant in the formulation of scenarios and hence influence the investigation. This can be helpful when the identified traces are in fact crime-related, and the scenario can thus be supplemented with information about the protagonist. However, the reverse may occur when the identified traces are not crime-related, and the CSI constructs a scenario with a wrong protagonist. Such scenarios may become leading in the unfolding investigation, and investigative actions may become too focused on finding incriminating evidence against the person identified through a database-match, while neglecting exonerating evidence [9,10].

A previous study on thought processes of CSIs having access to rapid identification technologies shows that early trace information leads to more accurate scenarios, but also to a onesided focus on presumed perpetrator traces that could be rapidly analysed [1,11]. This focus on presumed perpetrator traces can result in identifying perpetrators at a very early stage in the investigation; a very positive consequence of the technique. However, this can also result in too much attention for identifiable traces that are not crime-related, while other crime-related traces that are not quickly analysed are overlooked. To prevent this, CSIs need to distinguish crime-related traces from non-crime-related traces.

Expertise may help to identify relevant traces [12,13]. However, past experience can also cause premature closure when familiar characteristics of the crime scene lead to a categorisation of the scene and its traces, and to a corresponding routine strategy that is not suitable in that particular case $[14,15]$. If analysed traces are not crime-related but perceived as important, early identification of these traces can lead to incorrect hypotheses about the case [10]. This can affect the way experts distribute their attention and examine and evaluate further information [16].

It is clearly of the utmost importance that we understand more about how rapid identification information affects decision-making at the scene of the crime ideally before this technique becomes 
Identification at the crime scene

mainstream. Previous studies where CSIs were asked to conduct an investigation on a mock crime scene investigated the influence of the technologies on visual attention and the selection of traces by CSIs [1,11]. A more controlled study is necessary to investigate the interpretation of ID information and its influence on the interpretation of the crime scene in general. The present study therefore builds on De Gruijter et al., [1,11] by investigating the influence of rapid identification information on the interpretation of the crime scene and its traces.

\subsection{Rapid ID information}

Currently, CSIs base their interpretations on what they observe at the crime scene as well as on the information they receive from police officers. Before CSIs start their investigation at the scene, they are briefed about the situation by police officers. The police officers can provide information about the situation at the crime scene and about the victim. This information can be used to form hypotheses and decide on the potentially relevant traces observed at the scene [17].

Studies on police investigations show that detectives create a narrative account to make sense of all the information [3,4]. Identification information cannot currently play a role in their reconstruction at the scene, as the analysis of traces typically takes days, weeks or even months [18]. Without ID information, CSIs need to formulate scenarios based on the information they receive from the detectives and the assumed associations between observed traces at the scene. They will use their experience which results in heightened situational scanning and awareness [15] to predict where traces can be found. Crimes of the same type can share characteristics. Based on recognition of these characteristics CSIs can predict where the most useful traces can be found and which hypotheses should be considered $[19,20]$.

Once traces are analysed, these hypotheses can be tested with ID information once available and scenarios can be adjusted if necessary. However, cognitive processes like confirmation bias and belief perseverance could also influence the interpretation of the ID information when provided later. In general, people have the tendency to keep believing in a theory, even when confronted with falsifying evidence (i.e. belief perseverance). According to the theory of confirmation bias, falsifying evidence will be ignored or interpreted in a way it fits their theory. If one scenario becomes leading at the start of the investigation, ID information provided later may be interpreted in a way so that it fits this scenario, even when it suggests another suspect. After all, convinced of a theory, people (wittingly or unwittingly) recall only information that supports expectations and hypotheses and have difficulty changing their theory $[7,21]$.

The introduction of rapid identification technologies will make it possible to analyse traces and receive the results in situ, during the investigation at the scene. When ID information is already provided during the crime scene investigation itself, it could influence the interpretation of the scene and concurrent hypotheses. If a match is found, CSIs will rapidly receive information about the person who left the trace. Such information will provide extra clues that can be used to create or 
Identification at the crime scene

further complete a scenario about the event. The ID information could become dominant in the construction of a scenario as information presented early is generally given more weight than information acquired later [7]. This may be fine and will speed up the investigation if the information is interpreted in a correct way and leads to the right suspect. The risk however could be that CSIs start reasoning based on the ID information without actually considering the relevance of the traces.

Receiving a database-match does not mean that the trace has been left by the offender. It is important to consider the link between the trace and the crime before the results are provided, as also discussed by Broeders [22].

\subsection{The importance of a database-match}

To determine the relevance of traces, the context in which a trace is found is very important. Based on expertise, CSIs use this context to determine the link between traces and the crime. Ideally therefore, whether traces are perceived as relevant should thus not be influenced too much by the results of a database search, too early on. Obviously, when the results show that a trace is left by an innocent witness or by the victim, the results will influence the perceived context of the trace and the relevance of a trace. However, if a CSI expects a trace to be left by the perpetrator, it should not matter whether a match is found with a known person from the database or no match is found. The context of the trace has not changed based on the match. For instance, if two possible murder weapons are found at the crime scene and from one of the weapons a profile is obtained that matches a profile in the database, it should not be concluded that this murder weapon is more important than the one not producing a profile with a match in the database.

The CSIs in our previous study preferred to analyse assumed perpetrator traces and paid less attention to traces assumed to be left by other persons [11]. This is in line with findings of Baber and Butler [23] who demonstrated that expert CSIs were more focussed on obtaining evidence whereas lay persons tried to reconstruct the crime with more information. Their experience allows them to use automatic cognitive shortcuts and make fast decisions [15]. Due to a selective focus on obtaining evidence and catching the perpetrator, CSIs might assign more value to traces that produce a match with a known suspect in the database (should they have that information through Rapid ID). The match will provide a direct clue that CSIs may use, possibly resulting in a focus on incriminating evidence, thereby overlooking other relevant information.

Charlton, Fraser-Mackenzie and Dror [24] identified feelings of joy after they interviewed thirteen experienced fingerprints examiners who had successfully identified perpetrators. The examiners expressed a personal interest in catching criminals and solving crimes and they experienced feelings of joy when they discovered a match. CSIs may very well have the same feelings when conducting their investigation. Receiving a match might evoke a feeling of satisfaction as it provides a direct line of inquiry and could therefore influence their investigation. A focus on database-matches might be a good strategy when traces are obviously left by the offender, but risky if 
Identification at the crime scene

the crime scene is more ambiguous. Studies of Dror and colleagues [25-27] have shown that forensic experts are prone to errors when they have to compare ambiguous traces. The question is how CSIs will deal with ID information if the crime scene is ambiguous.

It is, therefore, essential to understand how the availability of rapid identification techniques will influence the interpretation of the crime scene and its traces, and how it will influence further investigation. The present study follows up the experiments with mobile technologies on the crime scene $[1,11]$. The goal of this study is to gain more insight into the influence of the rapid identification information on the reconstruction of the crime and the evaluation of traces by studying two questions, namely 1) is scenario formation influenced by the timing that ID information is provided and 2) do database matches influence the evaluation of traces and the reconstruction of the crime. Based on cognitive processes such as belief perseverance and confirmation bias it is predicted that ID information that is provided after a scenario is constructed will be interpreted in line with the most provisional scenario. Furthermore, a database match may increase the importance of a trace as receiving a match provides a direct clue in the investigation and can produce feelings of satisfaction. On the other hand, CSIs use their expertise to decide on the relevance of traces which could result in similar traces being perceived as equally important, regardless of a database-match. To investigate this experienced CSIs were asked to investigate a panoramic crime scene on a computer. Both the moment that ID information was provided to the participants and the traces that provided a databasematch or non-match were manipulated. The crime scene used in our previous study was relatively easy to interpret. In this study a more ambiguous crime scene was needed with multiple possible explanations for the traces to investigate the influence of ID information [28] and this further improved ecological validity. 
Identification at the crime scene

\section{Method}

To be able to investigate decision making at the crime scene we needed a crime scene and an event that caused the traces present at the crime scene. We will first elaborate on this stimulus material, which will be followed by the design of the experiment.

\subsection{Scenarios}

2.1.1 The ground truth - burglary scenario

The crime scenarios in our study are based on a real crime case and were constructed in collaboration with crime scene investigators. There were two possible main scenarios of which an aggravated burglary scenario was the ground truth. Two burglars, Ayden Roberts and John Campbell, killed a woman named Valerie by strangulation during a break in at her house. Valerie and her husband Steve got into a heated argument earlier that morning after Valerie admitted she was having an affair. Both of them left the house after the fight. In the meantime, the burglars entered their house. Valerie caught the burglars red handed when she came home. Ayden and John panicked and Valerie was strangled. Steve came home and found Valerie and called an ambulance. She was brought to the hospital where she died in intensive care. Colleagues at the hospital told the police that Valerie had unusual red marks on her neck. This story is the ground truth in our study.

\subsubsection{Alternative scenario - domestic homicide}

The scene was intentionally set up in an ambiguous way in order to thoroughly examine the research question and test the influence of ID information on the interpretation of the scene. In addition to the ground truth there is also a possible alternative interpretation of a domestic homicide in which Steve, the husband, killed his wife Valerie that fitted with the traces at the crime scene. The start of this alternative story is similar as the ground truth. Steve and Valerie had a heated argument in the morning and both of them left after the fight. Valerie came home first, followed by Steve. He strangled Valerie in a rage. Afterwards, he staged a burglary by opening the drawers and cupboards and called the ambulance.

\subsection{Traces left at the scene and information provided to participants}

In designing the crime scene it was clear that as a result of both the fight in the morning and the burglary in the afternoon, the crime scene needed to show a mess in the living room. During the burglary both Ayden and John left traces at the crime scene and obviously, Steve and Valerie's traces were found in the house as they were the residents.

It was suggested to participants that twelve traces or items from the scene were analysed with rapid identification technologies. Table 1 shows the items that showed a match with either one of the burglars or with the residents Steve and Valerie. Participants received the results of these traces. The 
Identification at the crime scene

information that these traces provided suggested a scenario with the potential involvement of two other persons (in effect Ayden and John), but this ID information also fit the alternative domestic homicide scenario as the traces left by the burglars are not strongly crime related and could be interpreted as being left during another occasion.

Table 1: traces that provided a match with burglars, Steve or Valerie.

\begin{tabular}{|l|l||l|l|}
\hline Trace & Match with & Trace & Match with \\
\hline \hline $\begin{array}{l}\text { Beer can outside the } \\
\text { house }\end{array}$ & Ayden & $\begin{array}{l}\text { Cigarette butt outside the } \\
\text { house }\end{array}$ & John \\
\hline $\begin{array}{l}\text { Outside post flap front } \\
\text { door }\end{array}$ & Ayden & $\begin{array}{l}\text { Outside of the window of } \\
\text { living room }\end{array}$ & John \\
\hline $\begin{array}{l}\text { Shoulder bag inside the } \\
\text { house (potential murder } \\
\text { weapon) }\end{array}$ & Ayden + Steve + Valerie & $\begin{array}{l}\text { Scarf inside the house } \\
\text { (potential murder } \\
\text { weapon) }\end{array}$ & John + Steve + Valerie \\
\hline $\begin{array}{l}\text { Glass on table } \\
\text { Coffee cup on table }\end{array}$ & Steve & Knife in the kitchen & Steve \\
\hline $\begin{array}{l}\text { Pieces of glass vase on } \\
\text { floor }\end{array}$ & Valerie & Cigarette butts ashtray & Valerie \& Steve \\
\hline
\end{tabular}

Participants also received preliminary findings from the detectives and forensic colleagues in the investigation, including information about the way the victim was found, a witness statement from Steve, from the neighbour and from a friend of Valerie and a friend of Steve. The witness statements are called investigative information and suggested the involvement of Steve (i.e. domestic homicide scenario).

\subsection{The crime scene}

We created an ambiguous crime scene with the traces that were mentioned above. The scene matched the burglary scenario as well as the domestic homicide scenario. The crime scene was created in the Netherlands in collaboration with Dutch expert crime scene investigators as part of a wider Dutch research project. The crime scene was based on a real case ensuring that traces were left at realistic places which makes the investigation as realistic as possible and therefore of more value to the enduser. We created a mock crime scene of the homicide case in one of the houses of the Dutch police academy, that are normally used for training purposes. In order to be able to collect enough data we photographed the crime scene with a panoramic camera which produced a 3D computer coverage of the scene. In this way, participants did not have to be physically present at the scene but could investigate it from behind the computer. They could navigate through the scene and zoom in and out. 
In addition, participants were provided more detailed photographs of the scene on paper. Figure 1 shows photos of the scene and the outlook of the panoramic scene on the computer.

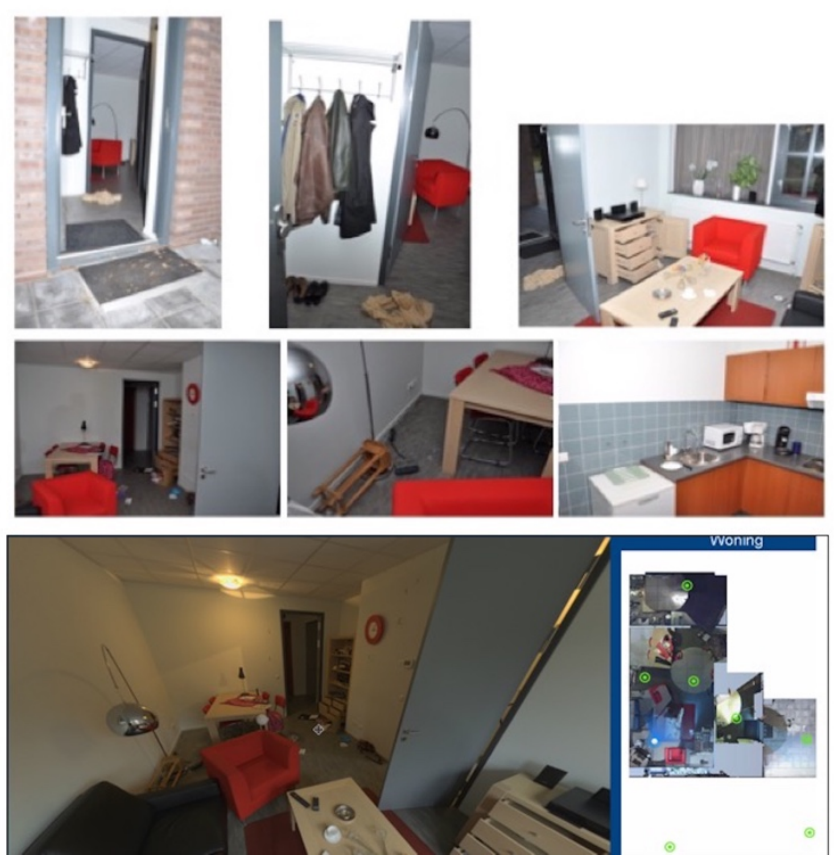

Figure 1: photos of the scene of the crime. The bottom photo on the left shows the outlook of the scene on the computer, the picture on the bottom right shows the plan of the house from a view from above. The green dots can be clicked on to view the house from another angle.

\subsection{Design}

Having explained the stimulus material we describe the design of the experiment. The experiment comprised a 2 (rapid ID information: before; after) x 2 (database match: with known person on set of traces 1 , no match on set 2; with known person on set of traces 2, no match on set 1) between participants design. ${ }^{1}$ In order to answer the research questions, variables were manipulated as follows.

\subsubsection{Q1: How is scenario formation influenced by the timing that ID information is provided?}

\section{Factor I: Rapid ID info}

Participants received analysis results of twelve pre-selected traces. They were told that these traces were analysed with rapid identification technologies and obtained profiles were searched against the National DNA database (NDNAD) and obtained fingermarks were searched against the database for fingerprints (IDENT1). In order to test whether scenario formation was influenced by the moment that ID information was provided, half of the participants were given the information at the start of their investigation, before they answered the questions (group 2: early ID). They were therefore able to use

\footnotetext{
${ }^{1}$ The design was tested in a pilot study with 64 university students. The results showed that the research questions could be answered by the manipulations in the present design.
} 
Identification at the crime scene

the information in their scenario formation. The other half received this information after they had written a provisional scenario and further investigated the scene (group 1: late ID). Hence, they had to write a scenario without the ID information. After these participants received the ID information they were offered the possibility to rewrite their scenario.

2.4.2 Q2: do database matches influence the evaluation of traces and the reconstruction of the crime? Factor II: database matches

In order to study whether database matches influence the evaluation of traces and the reconstruction of the crime, traces that provided a match with NDNAD or IDENT1 were manipulated. Two persons committed the crime and left traces at the scene: Ayden Roberts and John Campbell. We divided the participants into two groups, A: Ayden known/John unknown and B: Ayden unknown/John known. Being part of group A meant that Ayden was included in the database and John was not, so:

a) For traces left by Ayden participants received a match with Ayden Roberts

b) For traces left by John participants received the information that no match was found and the trace was left by unknown person $\mathrm{X}$

c) For traces left by Valerie or Steve participants received a match with Steve or Valerie. Being part of group B meant that John was included in the database and Ayden was not so the opposite counted:

a) For traces left by Ayden participants received the information that no match was found and the trace was left by unknown person $\mathrm{X}$

b) For traces left by John participants received a match with John Campbell

c) For traces left by Valerie or Steve participants received a match with Steve or Valerie. The traces left by Ayden and John are equally important. Figure 2 shows the traces left by both offenders. A trace on the window left by John and fingermarks on the post flap left by Ayden were both found outside the property. They could have been left by the offender, but could also have been left by an innocent person. The same goes for a cigarette butt and a beer can found outside. Traces of Ayden were also found on a cloth shoulder bag inside the house. John left traces on a scarf also found inside the house. Both the shoulder bag and the scarf could have been murder weapons as participants received information that the victim had unusual red marks on her neck, suggesting strangulation. Traces left by either Steve or Valerie were similar for both groups. Manipulating the traces that provided a match with Ayden or John allowed us to investigate the influence of receiving a databasematch on the value of a trace. The impact of getting an ID match on evaluation of traces was measured by the scores of these traces on a 7-point Likert scale. 


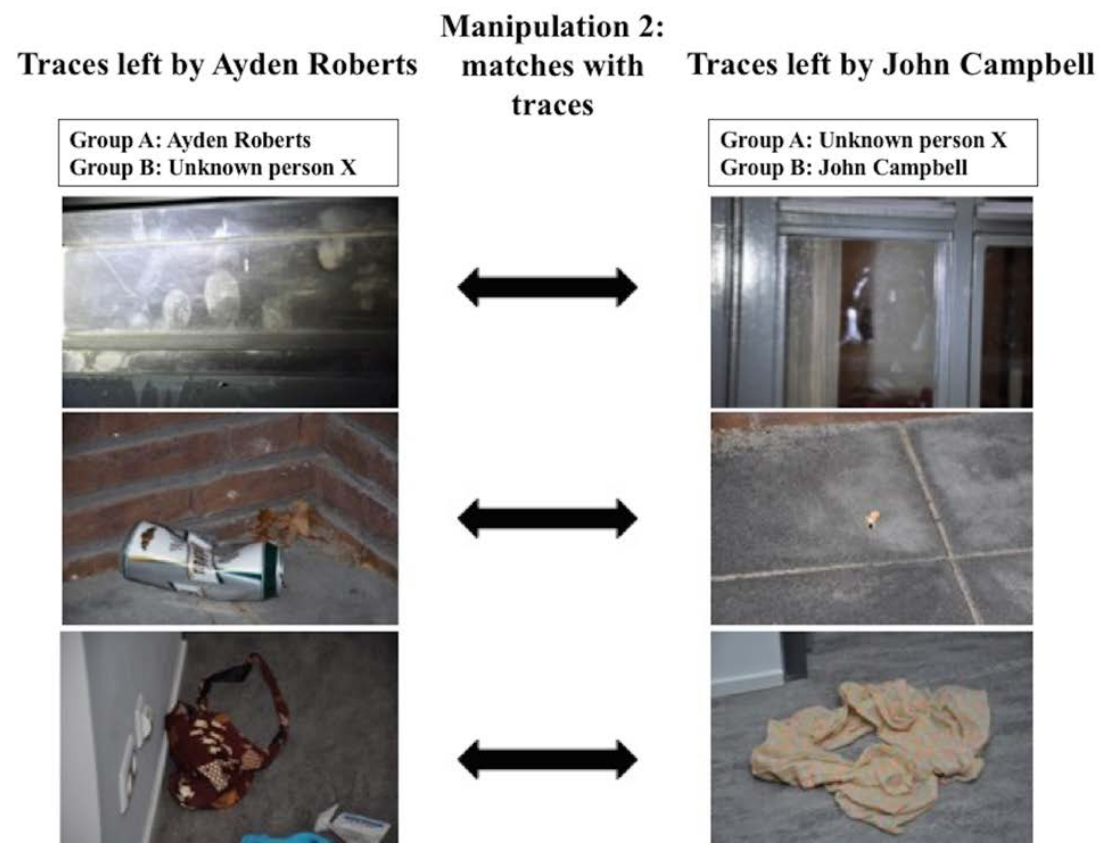

Figure 2: traces left by Ayden Roberts and John Campbell.

\subsection{Participants}

Table 2 shows the demographics of the participants. A total of 48 CSIs coming from eight police stations in four different regions in England participated in this study.

Table 2: Participant demographics.

\begin{tabular}{|c|c|c|c|}
\hline \multicolumn{4}{|c|}{ Characteristics $(\mathrm{N}=48)$} \\
\hline $\begin{array}{r}\text { Female } \\
\text { Male }\end{array}$ & $\begin{array}{l}28(58 \%) \\
20(42 \%)\end{array}$ & $\begin{array}{r}\text { Education } \\
\text { CSEs } \\
\text { GCSEs }\end{array}$ & $\begin{array}{l}3(6 \%) \\
3(6 \%)\end{array}$ \\
\hline $\begin{array}{r}<30 \\
30-39 \\
40-49 \\
50-59 \\
>60 \\
\text { Missing }\end{array}$ & $\begin{array}{r}4(8 \%) \\
14(29 \%) \\
16(34 \%) \\
6(13 \%) \\
2(4 \%) \\
6(13 \%)\end{array}$ & $\begin{array}{r}\text { A levels } \\
\text { Undergraduate study } \\
\text { Undergraduate degree } \\
\text { Masters degree }\end{array}$ & $\begin{array}{r}11(23 \%) \\
4(8 \%) \\
18(38 \%) \\
7(15 \%)\end{array}$ \\
\hline $\begin{array}{r}\text { Function } \\
\text { CSI } \\
\text { Crime scene manager } \\
\text { Other }\end{array}$ & $\begin{array}{r}36(75 \%) \\
10(21 \%) \\
2(4 \%)\end{array}$ & $\begin{array}{l}\text { Time spent in forensic } \\
\text { department (years) } \\
\begin{array}{l}M=12, S D=7 \\
\end{array} \\
\\
\end{array}$ & $\begin{array}{r}5(11 \%) \\
11(23 \%) \\
16(33 \%) \\
8(17 \%) \\
5(11 \%) \\
2(4 \%)\end{array}$ \\
\hline
\end{tabular}

\subsection{Procedure}


The sessions for the CSIs were held at the police stations in England where they were located. All participants received a form with information about the research, an informed consent form and were briefed about the investigation. Participants were instructed to imagine that they had to conduct a forensic investigation. It was explained that the crime scene was on the computer and the experimenter demonstrated to the participants how to navigate the environment on the outside of the house so as not to prime their responses inside. They were explicitly instructed to process the crime scene as much possible as if it were a real crime scene. The witness statements and ID information were given both on the computer and on paper. There was no time limit.

At the start of the investigation all participants received the same crime scene and the same investigative information that was obtained by statements of witnesses. Subsequently, all participants were asked to write a scenario about the event that had taken place at the crime scene. They were required to write only one most likely scenario. The late ID info group could base their scenario on the investigative information and the crime scene itself. The early ID information group had also received the identification information at the start of their investigation. The late ID info group received this ID information later in their investigation and were then offered the possibility to adjust their scenario. Furthermore, all participants had to score the importance of the twelve-preselected traces analysed with rapid identification technologies on a 7-point Likert Scale. Figure 3 shows the design of the study.
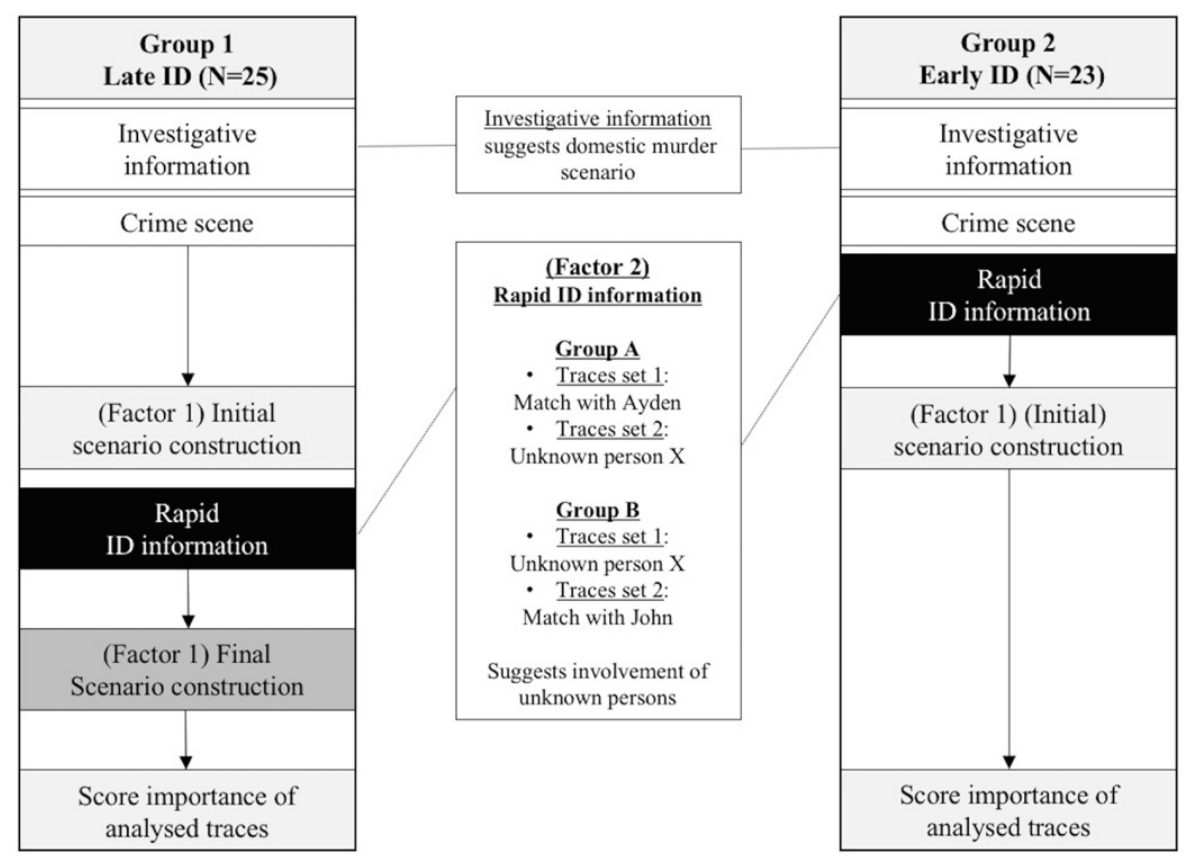

Figure 3: experimental design of the study. Factor 1 investigates the influence of the moment trace information is provided to the participants on the interpretation of the scene and factor 2 investigates the influence of the importance of a database-match on the value of a trace. 
Identification at the crime scene

\section{Results}

\subsection{Research question 1: will the timing of identification information affect scenario formation?}

The initial scenarios written by participants of group 1 (Late ID) and Group 2 (Early ID) are shown in table 3. The results show that 17 of the 25 CSIs in group 1 (Late ID) thought the husband committed the crime. Six CSIs described a different scenario with another perpetrator and two CSIs did not want to make a decision for one scenario. In group 2 (Early ID) eight CSIs thought the husband was the perpetrator. The group with identification information mostly described a burglary scenario.

Table 3: Classification of scenarios written by participants in terms of the offender.

\begin{tabular}{l|c|c}
\hline $\begin{array}{l}\text { In the scenario written } \\
\text { by the subject the crime was: }\end{array}$ & $\begin{array}{c}\text { Group 1 (late ID) } \\
\text { (n=25) }\end{array}$ & $\begin{array}{c}\text { Group 2 (early ID) } \\
\text { (n=23) }\end{array}$ \\
\hline \hline Domestic homicide (husband) & 17 & 8 \\
Aggravated Burglary & 4 & 11 \\
$\begin{array}{l}\text { Valerie killed by person she was } \\
\text { having an affair with }\end{array}$ & 2 & 2 \\
$\begin{array}{l}\text { Killer not husband, not further } \\
\text { defined }\end{array}$ & 0 & 1 \\
No decision & & \\
\hline \hline Total & 2 & 23
\end{tabular}

Unexpectedly, participants constructed scenarios in which Valeries' affair or another known person killed Valerie. In order to study the influence of ID information on the scenario construction it is important to understand what information (i.e. investigative information or ID information) was more important for the participants. For the affair scenarios, there is no proper distinction between the two sources of information as they could be based on both investigative or ID information. For that reason, the participants who wrote about an affair, the participants who did not define the killer, or made no decision are excluded from the analysis. The ones describing a "Domestic homicide" and “Aggravated burglary” will be further analysed.

A chi-square shows a significant effect of the ID information on the scenario that was constructed $\chi^{2}(1)=6.42, \mathrm{p}<.01$ (one sided). Without ID information, the majority described a domestic homicide scenario (81\%), whereas with ID information the majority described an aggravated burglary (58\%). Hence, the ID information helped participants construct a more accurate scenario (an aggravated burglary scenario).

All participants had to report the certainty they felt about their scenarios. No differences were found with respect to certainty about the scenario, as expressed by the participants. On a scale of 7 , 
Identification at the crime scene

the certainty level for CSIs in group 1 (Late ID) is $4.2(\mathrm{SD}=1.2)$ and $4.3(\mathrm{SD}=1.4)$ in group 2 (Early ID).

\subsubsection{Adjusted scenarios}

After participants of group 1 (Late ID) had written a scenario, they received ID information identical to the information that group 2 (Early ID) had been given earlier, and were given the opportunity to adjust their initial scenarios after further investigating the crime scene. The results show that a majority of the participants in group 1 (Late ID) rewrote their scenario (see table 4). In their initial scenario, 17 participants described a domestic homicide scenario and 4 CSIs described an "aggravated burglary" scenario. In the final crime decisions, these numbers switched to 1 domestic scenario and 11 burglary scenarios. Eight participants named John or Ayden as offender, but did not describe the crime type. One participant who made no decision in his initial crime scenario changed it into a burglary scenario with a different perpetrator. For this participant, the information helped deciding on one most provisional scenario. One participant stayed with his decision not to choose for one scenario. Three CSIs did not want to make a decision after receiving the ID info. They may have become confused of the new incoming information.

Table 4: cross tabulation of initial and final scenarios written by group 1 (Late ID).

\begin{tabular}{l|c}
\hline $\begin{array}{l}\text { In the scenario written } \\
\text { by the subject the crime was: }\end{array}$ & $\begin{array}{c}\text { CSIs } \\
\text { (N=24) }\end{array}$ \\
\hline \hline Domestic homicide (husband as offender) & 1 \\
Aggravated burglary & 11 \\
John / Ayden (crime type not described) & 8 \\
Valerie killed by person she was having an affair with or & 1 \\
other person known to her & \\
No decision for 1 scenario & 3 \\
\hline Total & 24 \\
\hline
\end{tabular}

Figure 4 shows the prevalence of initial and final scenarios for participants in group 1 (Late ID). We excluded the three participants who wrote a scenario with the category 'no decision' for the same reason as mentioned before. The categories 'aggravated burglary' and 'John/Ayden (crime type not described) are re-categorized into one category named 'homicide by John/Ayden'. Group 2 (Early ID), who received the ID information at the start of the investigation, wrote only one scenario during the study therefore their initial and final scenarios are identical and shown by a reference line. An exact Mc Nemar test investigating the influence of information within group 1 determined that there was a significant difference in the proportion aggravated burglary scenarios before and after the 
Identification at the crime scene

provision of the ID information $\chi^{2}(1)=10.29 \mathrm{p}<.001$. This shows that providing the ID information led to more accurate scenarios, a homicide by Ayden/John, within group 1 (Late ID). The ID information had no positive influence on the accurate number of offenders. Only one CSI changed from one offender to two offenders. The information had no influence on the certainty mean scores of scenarios. Before ID information was provided the mean score for group 1 (Late ID) was 4.1 ( $\mathrm{SD}=1.3$ ), after receiving ID information the mean score was 4.4 ( $\mathrm{SD}=1.1)$.

A comparison between the final scenarios of group 1 (Late ID) and the scenarios of group 2 (Early ID) shows a significant difference in the percentage that thought of a homicide by Ayden/John. Within the final scenarios of group 1 (Late ID), 95\% thought John or Ayden committed the crime, compared to the $58 \%$ in group 2 (Early ID) who received all the information at the start of their investigation $\chi^{2}(1)=7.56, p<.01$. Hence, at the end of the investigation greatest accuracy was achieved by CSIs in group 1 (Late ID). However, the ground truth is that the crime was in fact committed by two offenders. Only three CSIs wrote a final scenario with two offenders ( 1 in Late ID and 2 in Early ID).

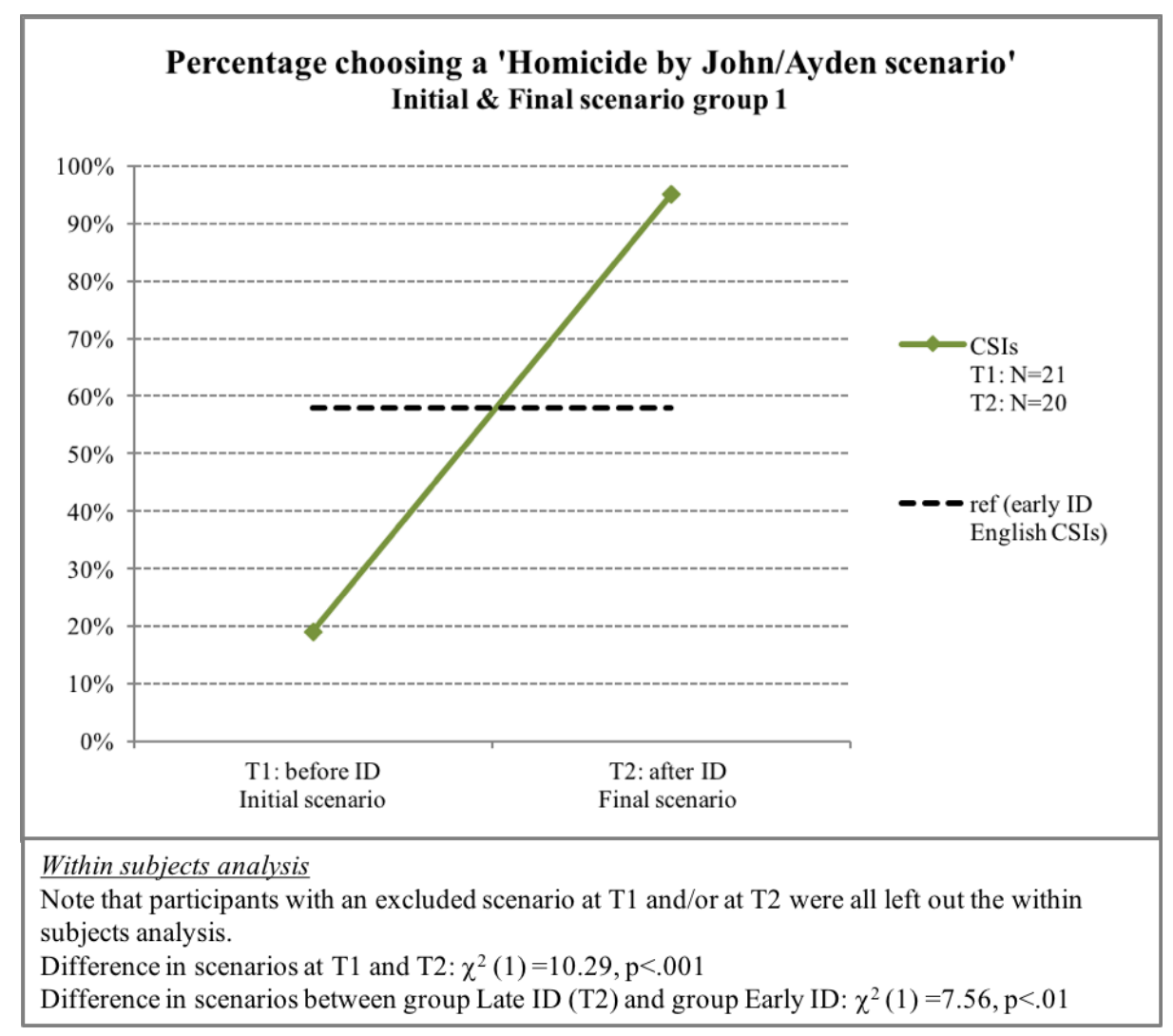

Figure 4: percentage CSIs choosing a homicide by John/Ayden scenario in group 1 at T1 without ID info and at T2 with ID info.

\subsection{Research question 2: did database matches influence the evaluation of traces and the} reconstruction of the crime 
As part of the data collection, all participants were asked to score the importance of the traces from which they received identification information on a 7-point Likert scale. Remember that group A received a match with Ayden for the traces left by Ayden and received "unknown person X" for the traces left by John. For group B it was vice versa. ${ }^{2} \mathrm{~A}$ t-test was conducted to compare the mean scores of all Ayden traces and all John traces between group A and group B. The results show a significant difference for the mean scores of all Ayden traces between group A ( $M=5.8, S D=1.4)$ and group $B$ $(\mathrm{M}=4.4, \mathrm{SD}=1.8) \mathrm{t}(45)=3.087, \mathrm{p}<.01$. The difference in mean scores of all John traces between group A $(M=5.2, S D=1.3)$ and group $B(M=5.9, S D=1.5)$ is not significant $t(45)=-1.823$, n.s. This indicates that particularly traces left by Ayden are perceived as more important by participants who received a database match compared to participants who received 'unknown person $X$ '. Traces left by John are scored equally important, regardless of a database-match. In general, these traces are perceived as more important $(M=5.5, S D=1.4)$ than traces left by Ayden $(M=5.1, S D=1.7)$, although the difference is not significant $\mathrm{t}(46)=-1.621$, n.s.

Table 5 shows the mean scores of the individual traces that matched with either John or Ayden for the participants in group A and B. The results show that the scarf (match with John) was rated significantly higher by the participants who received a match with John compared to those who did not receive a match $t(39.2)=-2.84, \mathrm{p}<.01$. Participants show a similar result for the shoulder bag: the group who received a match with Ayden rated the bag higher than the group who received the result that unknown person $X$ was on the bag (group $B$ ) $t(45)=3.53, p<.001$. The same goes for the beer can $\mathrm{t}(45)=2.18, \mathrm{p}<.05$ and the fingerprint on the post flap $\mathrm{t}(40.4)=2.74, \mathrm{p}<.01$. This suggests that CSIs are more focussed on the traces that showed a match with a known offender. The cigarette butt and trace on the window were not rated differently. ${ }^{3}$

Table 5: mean relevance scores of the traces that matched with either John or Ayden for the participants in group A (“Ayden”- “unknown person”) and B (“unknown person” - “John”).

\footnotetext{
${ }^{2}$ A factorial Anova showed no significant effect of the moment trace information was provided (condition late vs early). All participants were divided into group A and B, i.e. Ayden or John.

${ }^{3}$ The traces left by Steve and Valerie were scored equally important over the conditions, except for blood on the tissue which was rated as more important by the experts in group $\mathrm{B} t(45)=-2.78, \mathrm{p}<.01$.
} 
Identification at the crime scene

\begin{tabular}{|c|c|c|c|c|c|c|c|}
\hline \multicolumn{8}{|c|}{$\begin{array}{l}\text { Average on 7-point Likert Scale } \\
\text { (1 very unimportant }-7 \text { very important) }\end{array}$} \\
\hline $\begin{array}{l}\text { Trace type } \\
\text { (points to) }\end{array}$ & $\begin{array}{c}\text { A: } \\
\text { Ayden/ } \\
\text { Unknown } \\
(\mathbf{N}=\mathbf{2 3})\end{array}$ & $\begin{array}{c}\text { B: } \\
\text { unknown/ } \\
\text { John } \\
(\mathbf{N}=\mathbf{2 4})\end{array}$ & $\begin{array}{c}\text { t-test for } \\
\text { difference } \\
P\end{array}$ & $\begin{array}{l}\text { Trace type } \\
\text { (points to) }\end{array}$ & $\begin{array}{c}\text { A: } \\
\text { Ayden/ } \\
\text { Unknown } \\
(\mathbf{N}=\mathbf{2 3})\end{array}$ & $\begin{array}{c}\text { B: } \\
\text { unknown/ } \\
\text { John } \\
(\mathbf{N}=\mathbf{2 4})\end{array}$ & $\begin{array}{c}\text { t-test for } \\
\text { difference } \\
\text { P }\end{array}$ \\
\hline Scarf(John) & 5.83 & 6.71 & .007 & $\begin{array}{l}\text { Beer can } \\
\text { (Ayden) }\end{array}$ & 5.57 & 4.25 & .034 \\
\hline $\begin{array}{c}\text { Shoulder bag } \\
\text { (Ayden) }\end{array}$ & 6.13 & 4.63 & .001 & $\begin{array}{l}\text { Window } \\
\text { trace } \\
\text { (John) }\end{array}$ & 5.09 & 5.83 & n.s. \\
\hline $\begin{array}{c}\text { Cigarette butt } \\
\text { (John) }\end{array}$ & 4.78 & 5.17 & n.s. & $\begin{array}{c}\text { Fingermar } \\
\text { k post flap } \\
\text { (Ayden) }\end{array}$ & 5.78 & 4.29 & .009 \\
\hline
\end{tabular}

*Scores in conditions where a participant gets a name returned are highlighted in yellow

\subsubsection{Within subjects analysis}

Besides the between-subjects analyses, a within-subjects analysis was conducted to investigate the influence of a database-match on the perceived importance within persons. A paired sample t-test shows a significant difference in perceived importance between traces that were linked with the database or with unknown person X. Within group A the traces left by the person included in the database (Ayden) show a higher mean $(\mathrm{M}=5.8, \mathrm{SD}=1.4)$ than traces left by the person not in the database (John) $(\mathrm{M}=5.2, \mathrm{SD}=1.3) \mathrm{t}(22)=2.492, \mathrm{p}<.025$. This effect is shown to an even higher degree for participants in group B: traces left by the person in the database (John) were scored higher $(M=5.9, S D=1.5)$ than traces left by the person not included in the database $(M=4.4, S D=1.8) t(23)=$ 4.185, $\mathrm{p}<.001$.

Figure 5 shows the differences in mean scores per pair of traces for participants of group A and group B. Participants of group A scored only the cigarette butt and beer can significantly different $\mathrm{t}(22)=-2.543, \mathrm{p}<.025$. The shoulder bag and the post flap (traces linked with a person in the database) were not perceived as more important than the comparable traces without a match with the database (the scarf and window trace). The perceived importance of traces in group B shows a higher influence of a database-match. Both the scarf and trace on the window were scored as more important than the comparable traces without a link with a person in the database (bag and post flap), scarf-bag t(23)= 5.346, $\mathrm{p}<.001$ and window trace-post flap $\mathrm{t}(23)=3.019, \mathrm{p}<.01$. The difference between the cigarette butt and beer can is not significant. 
Identification at the crime scene

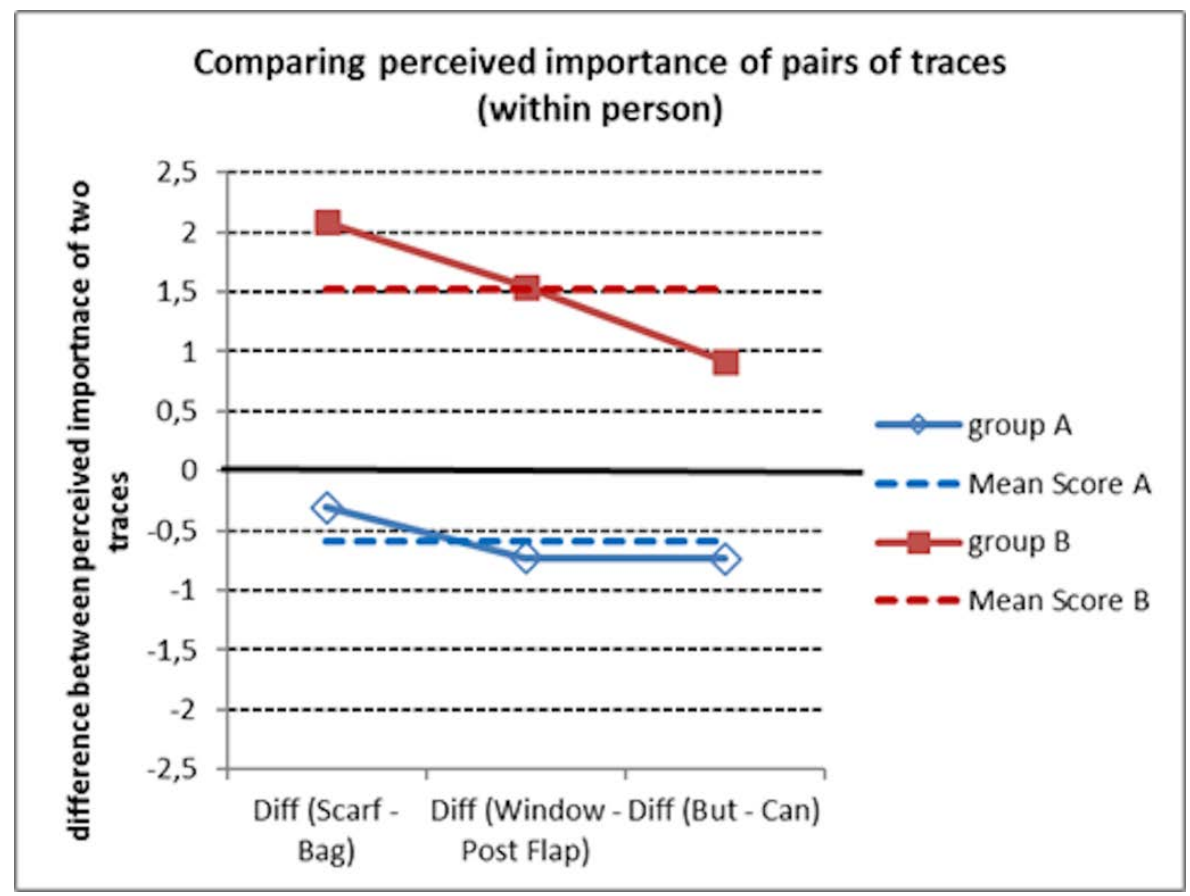

Figure 5: mean difference between perceived importance of three pairs of traces between group A and group B.

* means are computed recognizing one missing value in group A for Diff (window - post flap) 
Identification at the crime scene

\section{Discussion}

Our findings suggest that rapid feedback of results of trace analyses, i.e. identification information, and more specifically, the timing that this information is provided, influences the scenario formation of CSIs. When ID information was not provided and scenarios had to be formed based on observations at the crime scene and the available investigative information, CSIs were guided by the hypotheses of the investigative information coming from mostly witness statements. CSIs who received ID matches at the start of the investigation, before a scenario was formed, came up with a different scenario showing an influence of this ID information. The influence of prior information corresponds with findings of Van den Eeden, De Poot and Van Koppen [17] who demonstrated that CSIs are influenced by information provided prior to their investigation. Furthermore, contrary to expectations based on theories of confirmation bias and belief perseverance [7,21], ID information had an even greater influence on scenario formation when provided after an initial scenario was formed. Although information provided early is generally given more weight [7], ID information became even more dominant in scenario construction when provided later. CSIs changed their initially formed scenario to a different story once the ID information was presented to them. In this case, providing the ID information after an initial scenario was formed helped CSIs make a more accurate interpretation of the scene.

We hypothesize that the research suggests that scenario construction might be more challenging when information from a variety of sources are present, even more so if these are conflicting, and, have to be processed at the same time as there are known limitations on the amount of information that people are able to receive, process, and remember [29]. If scenarios can be constructed based on one set of information and tested with new incoming information, it might be less challenging to understand the information. CSIs make sense of their observations at the scene whereby they form hypotheses that best describe their data. The inference process that leads to a hypothesis or scenario of what may have happened is also called abduction. If a provisional explanatory scenario is present, later incoming ID information can be used to test this scenario. At this point in the investigative process, it may be more evident that the information suggests a different scenario and therefore leads to refutation of the provisional scenario [30,31]. This process of hypothetico-deductive reasoning where information is not provided at once but is distributed over time may ease scenario construction and testing by easing cognitive load at the start and may improve the accuracy of the outcome [29]. Broeders [22] also suggests to consider scenarios based on observations at the scene, without information about the sources. ID information can then be used to test scenarios instead of constructing a scenario with this information. It reduces the chance of reasoning based on database-matches.

We are led to the conclusion that CSIs seem to be keen on information that other persons besides the residents, were linked to the crime scene. In our experiment, the alien marks were indeed left by offenders, so the ID information helped constructing an accurate scenario. However, the 
objects on which the traces were found were not evidently related to the offence, so these traces could also had been left by innocent persons. Notice that the demonstrated impact of ID information may tempt police officers to focus too early on an actually innocent suspect [10,32]. We suggest that further research should test if the amount of traces that match with one person influences the value attached to these traces.

Our findings show that CSIs strongly focus on traces that show a match with a known person in the database. Receiving a database-match made traces more important than similar traces left by an unknown person, although the context in which the trace was found was not changed by this match. This effect was not shown for all traces, because the trace-pairs did not appear to be as equally important as we expected. Yet, it is important that attention is paid to it as it can result in missing important information. Receiving a name provides a direct line of inquiry for detectives, possibly resulting in an increased perceived importance of the trace. Understandably, CSIs might experience feelings of joy after a match is found as it may produce a great progression in the investigation. Experienced fingerprints examiners interviewed in the study of Charlton and colleagues [24] experienced similar feelings after a match is discovered. However, generally speaking, traces found in a similar context but without a link to a known person should not be treated differently as it increases the chance of missing important traces, since not all offenders are included in the database.

Hence, CSIs showed selectivity: they considered the traces linked to a known offender as more important than the traces linked to an unknown person. This focus on potential evidence fits in with the study of Baber and Butler [23] where CSIs focus on colleting potential evidence and less other information. Making shortcuts, due to more dense cognitive schemas [33], can be efficient for experts, but it could also be a pitfall when important traces are overlooked. Experience is not always beneficial, experts may become stuck in patterns $[14,16]$. Based on their experience, CSIs have developed heuristics that help make fast and frugal decisions, especially helpful in situations that require complex decisions and actions under time pressure [16], like crime scene investigations. Selectivity can be helpful and efficient (an important aspect in the English model of policing [34]), but errors can occur when heuristics are applied too easily and experts should avoid the risk of becoming over-confident in their task [15,16]. In our experiments all traces were important, because the ground truth of the set-up was that the crime was committed by two offenders. However, only three CSIs developed a scenario with two offenders.

Although our scene was based on a real crime scene and the influence of database-matches on the interpretation of the scene and the perceived importance of traces can only be measured with use of controlled experiments, these kind of experiments also have limitations. A clear limitation of the study is the fact that participants were asked to conduct a crime scene investigation on a computerized crime scene in a controlled setting, which is of course not representative of CSIs actual work. All participants were asked to what extent it had been possible to properly answer the questions on the basis of the computerized scene and the photos, using a 7-point Likert scale. CSIs scored a 3.5, 
showing that they had some difficulty interpreting the artificial scene as a real crime scene. Nevertheless, the main purpose of the study was to examine the influence of ID information on scenario construction and we approached this question by comparing what happened within that setting, which in our opinion, enables us to investigate this question. A real crime scene would be beneficial if the main purpose is to study the methods used at a scene. Other studies have also demonstrated the influence of information in police investigations in controlled settings $[10,17,35]$. Moreover, results show that we were indeed successful in manipulating the relevance of ID information for the participants.

The results did not support our prediction that ID information provided later in the investigation would fail to change the scenarios produced over time, due to processes of confirmation bias and belief perseverance. Instead, the majority of the CSIs did indeed change their scenario based on the ID information. Possibly, the fact that exclusively this information was provided at a later stage did elicit the feeling that the information was important and therefore ought to be used. In further studies, it might be useful to provide different kinds of information, both investigative and forensic, at different moments during the crime scene investigation, in order to diminish attention on one explicit information moment. This would also provide more insights into the scenario construction process and the moment confirmation bias and related processes come into play.

A final limitation of the study might be that participants were forced to make a decision for one preferred scenario. Especially CSIs told us that they had difficulty writing only one preferred scenario at such an early phase of the investigation. Normally, according to the CSIs themselves, they try to remain open-minded during the first phase of the investigation. Notice however, that several studies have shown that information can unintentionally influence perception and decision making $[28,36]$, which may result in CSIs generating a provisional preference for one scenario after they have observed the scene and processed the available information. This preference could be of influence on the further investigation.

Despite these limitations, this study demonstrated that providing ID information during the crime scene investigation potentially influences scenario construction of CSIs. The moment this information is provided influences to what extent it is used. Also, CSIs seem to attach great value to traces that produce matches with databases and hence yield a name of a known person. It is questionable whether selectivity in this way is desirable. Ideally, receiving a database-match should not be a determining factor when deciding on the importance of a trace. The context in which the trace is found should determine the relevance of a trace. This study is one of the first studies investigating the effects of providing ID information during the investigation and more studies are needed to be able to inform policy makers about opportunities and dilemmas of the new technologies. Nevertheless, it has unearthed some important findings about the way information may be processed by experts at the scene of the crime and has paved the way for future studies. 
Identification at the crime scene 
Identification at the crime scene

\section{References}

[1] M. de Gruijter, C.J. de Poot, H. Elffers, The Influence of New Technologies on the Visual Attention of CSIs Performing a Crime Scene Investigation, J. Forensic Sci. 61 (2016) 43-51.

[2] M. Holland, F. Wendt, Evaluation of the RapidHIT 200, an automated human identification system for STR analysis of single source samples, Forensic Sci. Int. Genet. 14 (2015) 76-85. doi:10.1016/j.fsigen.2014.08.010.

[3] M. Innes, Investigating murder: Detective work and the police response to criminal homicide, Oxford University Press, Oxford, 2003.

[4] W.A. Wagenaar, P.J. van Koppen, H.F. Crombag, Anchored narratives: The psychology of criminal evidence, St Martins’s Press, 1993.

[5] I. Fahsing, K. Ask, The making of an expert detective: the role of experience in English and Norwegian police officers’ investigative decision-making, Psychol. Crime Law. 22 (2016) 203-223. doi:10.1080/1068316X.2015.1077249.

[6] M. Wright, Homicide detectives’ intuition, J. Investig. Psychol. Offender Profiling. 10 (2013) 182-199. doi:10.1002/jip.1383.

[7] R.S. Nickerson, Confirmation bias: A ubiquitous phenomenon in many guises, Rev. Gen. Psychol. 2 (1998) 175-220. doi:10.1037/1089-2680.2.2.175.

[8] D.K. Rossmo, Criminal investigative failures, CRC Press, 2008.

[9] S.M. Kassin, C.C. Goldstein, K. Savitsky, Behavioral confirmation in the interrogation room: on the dangers of presuming guilt, Law Hum. Behav. 27 (2003) 187-203.

[10] B. O’Brien, Prima suspect: An examination of factors that aggravate and counteract confirmation bias in criminal investigations, Psychol. Public Policy Law. 15 (2009) 315-334.

[11] M. de Gruijter, C.J. de Poot, H. Elffers, Reconstructing with trace information: does rapid identification information lead to better crime reconstructions?, J. Investig. Psychol. Offender Profiling. (2016). doi:10.1002/jip.1471.

[12] G.A. Klein, A recognition-primed decision (RPD) model of rapid decision making, Ablex publishing corporation New York, New York, 1993.

[13] J. Shanteau, How much information does an expert use? Is it relevant?, Acta Psychol. (Amst). 81 (1992) 75-86. doi:10.1016/0001-6918(92)90012-3.

[14] D. Kahneman, Thinking fast and slow, Penguin, 2012.

[15] C. Nee, T. Ward, Review of expertise and its general implications for correctional psychology and criminology, Aggress. Violent Behav. 20 (2015) 1-9. doi:10.1016/j.avb.2014.12.002.

[16] I.E. Dror, The paradox of human expertise: why experts get it wrong., in: N. Kapur (Ed.), Parad. Brain, Cambridge University Press, Cambridge, 2011: pp. 177-188. doi:10.1007/978-161779-095-9.

[17] C.A.J. van den Eeden, C.J. de Poot, P.J. van Koppen, Forensic expectations: Investigating a crime scene with prior information, Sci. Justice. (2016). doi:10.1016/j.scijus.2016.08.003. 
Identification at the crime scene

[18] A.A. Mapes, A.D. Kloosterman, C.J. de Poot, DNA in the Criminal Justice System: The DNA Success Story in Perspective, J. Forensic Sci. 60 (2015) 851-856. doi:10.1111/15564029.12779.

[19] M. Groen, C. Berger, Crime scene investigation, archaeology and taphonomy: reconstructing activities at crime scenes, in: E. Schotmans, N. Marquez-Grant, S. Forbes (Eds.), Taphon. Hum. Remain. Forensic Anal. Dead Depos. Environ., Wiley-Blackwell, (in press).

[20] A. Jamieson, A rational approach to the principles and practice of crime scene investigation: I. principles, Sci. Justice. 44 (2004) 3-7.

[21] J. Klayman, Varieties of Confirmation Bias, Psychol. Learn. Motiv. - Adv. Res. Theory. 32 (1995) 385-418. doi:10.1016/S0079-7421(08)60315-1.

[22] A.P.A. Broeders, Op zoek naar de bron: Over de grondslagen van de criminalistiek en de waardering van het forensisch bewijs, Kluwer, Deventer, 2003.

[23] C. Baber, M. Butler, Expertise in crime scene examination: comparing search strategies of expert and novice crime scene examiners in simulated crime scenes., Hum. Factors. 54 (2013) 413-423.

[24] D. Charlton, P.A.F. Fraser-Mackenzie, I.E. Dror, Emotional experiences and motivating factors associated with fingerprint analysis, J. Forensic Sci. 55 (2010) 385-393. doi:10.1111/j.1556-4029.2009.01295.x.

[25] I.E. Dror, D. Charlton, Why experts make errors, J. Forensic Identif. 56 (2006) 600-616. doi:Doi: 10.1016/s1355-0306(98)72118-5.

[26] I.E. Dror, D. Charlton, A.E. Péron, Contextual information renders experts vulnerable to making erroneous identifications, Forensic Sci. Int. 156 (2006) 74-78. doi:10.1016/j.forsciint.2005.10.017.

[27] I.E. Dror, G. Hampikian, Subjectivity and bias in forensic DNA mixture interpretation, Sci. Justice. 51 (2011) 204-208. doi:10.1016/j.scijus.2011.08.004.

[28] D.M. Risinger, D. Michael, M.J. Saks, C. William, The Daubert / Kumho Implications of Observer Effects in Forensic Science: Hidden Problems of Expectation and Suggestion The Harvard community has made this article openly Please share how this access benefits you . Your story, Calif. Law Rev. 90 (2002) 1-56. doi:10.15779/Z38GM7K.

[29] G.A. Miller, The magical number seven plus or minus two: some limits on our capacity for processing information, Psychol. Rev. 63 (1956) 81-97.

[30] D. Carson, The abduction of Sherlock Holmes, Int. J. Police Sci. Manag. 11 (2009) 193-202. doi:10.1350/ijps.2009.11.2.123.

[31] C. Roux, F. Crispino, O. Ribaux, From Forensics to Forensic Science, Curr. Issues Crim. Justice. 24 (2012) 7-24.

[32] K.A. Findley, M.S. Scott, The Multiple Dimensions of Tunnel Vision in Criminal Cases, Wis. L. Rev. 2 (2006) 292-397. 
Identification at the crime scene

[33] S.T. Fiske, S.E. Taylor, Social cognition, McGraw-Hill, 1991.

[34] T.P. Winsor, State of Policing. The Annual Assessment of Policing in England and Wales., 2016. http://www.justiceinspectorates.gov.uk/hmic/wp-content/uploads/state-of-policing2015.pdf.

[35] K. Ask, P.A. Granhag, Motivational sources of confirmation bias in criminal investigations: the need for cognitive closure, J. Investig. Psychol. Offender Profiling. 2 (2005) 43-63. doi:10.1002/jip.19.

[36] S.M. Kassin, I.E. Dror, J. Kukucka, The forensic confirmation bias: Problems, perspectives, and proposed solutions, J. Appl. Res. Mem. Cogn. 2 (2013) 42-52. doi:10.1016/j.jarmac.2013.01.001. 